\title{
PROFIRIA AGUDA: O QUE PRECISAMOS SABER
}

\section{ACUTE PORPHYRIA: WHAT DO WE NEED TO KNOW}

DOI: $10.5380 /$ rmu.v1i1.40681

\author{
Felipe Wolff Schwambach ${ }^{1}$, Patricia Albizu Piaskowy ${ }^{1}$, Marja Carolina Rufino dos Santos ${ }^{1}$, \\ Camila Gallo Pilger', Glbran Avelino Frandoloso
}

\section{RESUMO}

As porfirias são patologias relacionadas a um defeito metabólico presente na via de biossíntese do heme. São doenças pouco conhecidas, e por serem raras, com sintomas inespecíficos e com uma variedade ampla na sua apresentação, muitas vezes ocorre atraso no diagnóstico, com demora no tratamento e piora do prognóstico. Podem ser divididas em porfirias cutâneas e agudas, com manifestações neurológicas ocorrendo nessa última. Esse artigo visa uma revisão sobre as porfirias agudas e esclarecimento sobre o assunto.

Palavras chave: porfiria, doenças metabólicas, manifestações clínicas, neuropatia.

\section{ABSTRACT}

The porphyrias can be considered as a pathology related to a metabolic defect in the biosynthesis pathway of the heme. They are rare and not very well know diseases, what in addiction to a wide range of presentations and symp-toms leads to a delay in the diagnosis, treatment and poor prognosis. They can be classified into cutaneous and acute porphyria - this second characterized by neurologic symptoms. The meaning of this paper is to review about acute porphyrias.

Key-words: Epidemiology. Sensibility. Multi-drug resistant organisms. 


\section{CASO CLÍNICO}

Paciente feminina de 28 anos, previamente hígida e sem uso regular de medicações. Inicia com dor abdominal difusa associada a parestesia em mão direita. Evolui com parestesia em todo o membro superior direito e membros inferiores, associado à redução da força muscular de forma ascendente. Também apresenta taquicardia sem febre, desorientação com episódios de delírio e dor por todo corpo, principalmente membros. Evolui para tetraplegia e insuficiência ventilatória com necessidade de intubação orotraqueal. Sem sinais de irritação meníngea; bem como alterações ao exame cardiopulmonar ou abdominal. Tomografia computadorizada e ressonância nuclear magnética de crânio sem alterações, assim como eletrólitos séricos, parcial de urina, hemograma com contagem de plaquetas e provas inflamatórias. Culturas de sangue, urina e líquor negativos para bactérias e exame para HIV negativo.

Diante de um paciente com sinais e sintomas como dor abdominal, taquicardia, parestesia de membros ou redução da força muscular, psicose ou delírios, náusea, vômitos ou constipação, uma hipótese a ser investigada é de porfiria aguda. Essas doenças raras ocorrem com sintomas arrastados e inespecíficos, muitas vezes sendo subdiagnosticadas. O principal diagnóstico diferencial é com a síndrome de GuillainBarré, mas as vasculites e intoxicação por chumbo também devem ser investigados. Nesse artigo serão revisados os aspectos clínicos das porfirias agudas.

\section{INTRODUÇÃO}

As porfirias são patologias associadas a defeitos metabólicos na biossíntese do heme $\mathrm{e}^{1-9}$. 0 heme é composto por um íon ferroso e um anel tetrapirrólico denominado protoporfirina IX, que para alcançar a sua estrutura final passa por um complexo pro-cesso de conversão a partir de resíduos de glicina e succinil-CoA, com posterior quelação de ferro ${ }^{1-3,5-9}$. Esse fenômeno é catalisado em oito estágios enzimáticos ${ }^{1-9}$ (Figura 1). Deficiências na produção das sete últimas enzimas envolvidas dão origem aos sete tipos de porfirias, cada qual referente à sua enzima deficiente no organismo. São eles, na ordem respectiva de etapas enzimáticas deficientes: porfiria com deficiência de ALA dehidratase (PAD), porfiria intermitente aguda (PIA), porfiria eritropoiética congênita, porfiria cutânea tarda (PCT), coproporfiria hereditária $(\mathrm{CPH})$, porfiria variegada $(\mathrm{PV})$ e protoporfiria eritropoiética (PPE) ${ }^{1-9}$.

Os órgãos nos quais a produção do heme é mais marcante são a medula óssea - onde há alta demanda desta molécula para a síntese tanto de

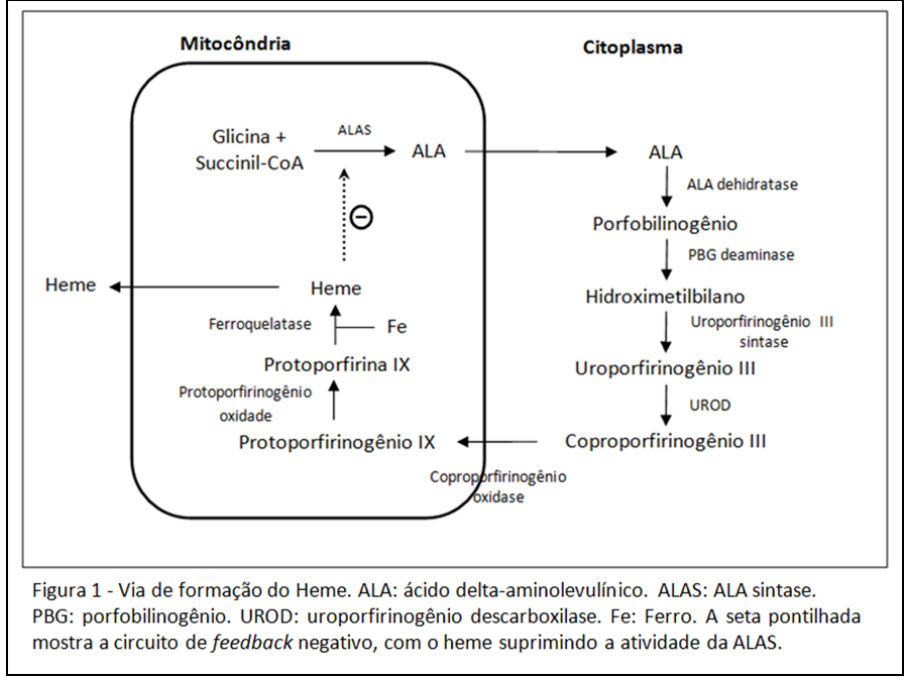

hemoglobina quanto de outras hemoproteínas - e o fígado, pois o heme é constituinte de diversas proteínas, em especial do cito-cromo p450 1,3,5.

As manifestações clínicas das porfirias se devem ao acúmulo de substâncias intermediárias da via de produção do heme, que não puderam ser convertidas no produto final devido à deficiência enzimática ${ }^{5,8-9}$. Essas substâncias tem efeito neurotóxico ${ }^{5,9}$, com destaque para o ácido deltaaminolevulínico (ALA $)^{6,9}$ e o porfobilinogênio ${ }^{6,7,9}$. Também desencadeiam fotossensibilidade pelo seu acumulo na pele ${ }^{9}$, causando lesões cutâneas de grau variável após exposição solar.

Podem ser classificadas quanto ao local de maior acúmulo dos intermediários do heme como eritropoiéticas (PEC e PPE) ou hepáticas (PAD, PIA, PCT, $\mathrm{CPH}$ e $\mathrm{PV})^{1,2,8,9}$. Também podem ser classificadas pelas manifestações clínicas majoritárias ${ }^{1,8,9}$ como porfirias agudas - cuja manifestação se dá por surtos neurológicos, característicos das porfirias hepáticas com exceção da PCT8,9. E porfirias cutâneas - incluem a PCT e os dois tipos de origem eritropoiética ${ }^{9}$ (Figura 2). A $\mathrm{CPH}$ e a PV podem cursar com sintomas neurológicos e cutâneos, sendo as vezes denominado como tipo misto ${ }^{1,2}$. Apesar do termo porfiria aguda, este não descreve corretamente as manifestações clínicas, que podem ser crônicas e persistentes ${ }^{8}$.

As porfirias são essencialmente doenças genéticas, sendo as de herança autossômica recessiva a PAD e a PEC ${ }^{1,2,5-9}$. As demais têm padrão autossômico dominante ${ }^{1,2,5-9}$. Ocorre penetrância incompleta ${ }^{6-10}$, estimando-se que $80 \%$ dos pacientes que apresentam uma mutação que determine a deficiência enzimática nunca desenvolverão sintomas da doença - sendo chamada de porfiria latente ${ }^{7}$. A porfiria cutânea tarda, o tipo mais comum, está fortemente relacionada a fatores ambientais, sendo na maior parte das vezes adquirida ${ }^{9}$.

A primeira enzima da via, ácido deltaaminolevulinico sintase (ALAS), é o passo limitante de 


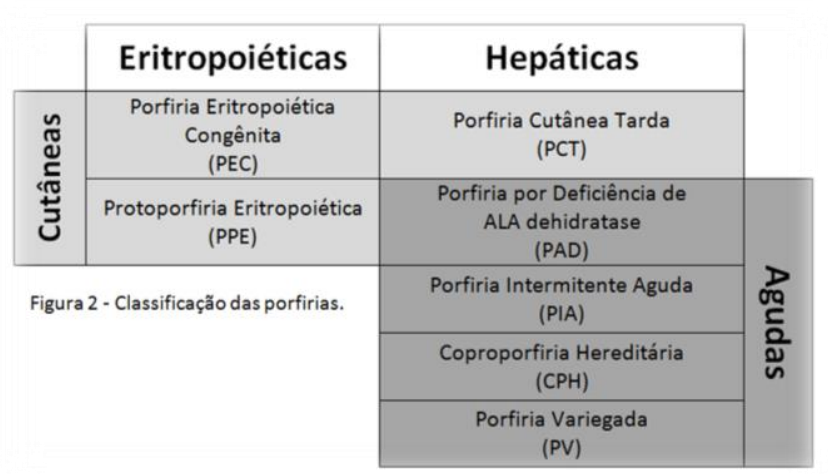

toda a reação $0^{5-8}$. Dessa forma, na porfiria, substâncias que aumentam sua atividade levam ao acúmulo de substratos intermediários da via e podem desencadear a sintomatologia da porfiria ${ }^{6}$. Exemplos são o tabaco, álcool, alguns medicamentos, drogas ou mesmo estados inflamatórios/infecciosos, jejum prolongado, stress e stress cirúrgico ${ }^{6-8,10}$. Também hormônios endógenos, principalmente a progesterona, podem ser causas de agudização da doença, explicando porque esses ataques são mais frequentes em mulheres ${ }^{8,10}$. De forma oposta, substâncias que regulam negativamente a ALAS diminuem a velocidade da via metabólica e reduzem o acúmulo de intermediários tóxicos, como ocorre com a glicose, o heme (feedback negativo) e a Hematina, elemento extraído do sangue humano semelhante ao heme ${ }^{6,7}$.

\section{MANIFESTAÇÃOES CLÍNICAS}

As porfirias agudas são doenças cujo curso assintomático intercala-se com períodos de exacerbação e manifestação clínica. Os sinais e sintomas da exacerbação envolvem alterações neurológicas ${ }^{9}$, podendo ser resultado da disfunção do sistema nervoso autonômico, periférico ou central ${ }^{6}$. O curso clínico pode ser agudo ou mais arrastado, assim como autolimitado ou progressivo ${ }^{7}$.

\section{Neuropatia Autonômica}

A dor abdominal é o sintoma mais comum da crise ${ }^{6,8-11}$, sendo difusa e inespecífica 8 e geralmente acompanhada de náusea, vômitos, constipação ou diarréia ${ }^{5-8}$; desencadeada por gastroparesia e pseudoobstrução pela neuropatia esplâncnica ${ }^{5,6}$. A taquicardia é outra manifestação comum ${ }^{5,6,11}$, podendo preceder a neuropatia periférica em várias semanas ${ }^{6,12}$. Pode haver disfunção esfincteriana, diaforese, hipertensão e menos comumente hipotensão postural ${ }^{5-7,11}$. Arritmias cardíacas podem ocorrer sendo uma causa importante de óbito ${ }^{7}$.

\section{Neuropatia Autonômica}

É primariamente motora ${ }^{7,8}$, sendo este um achado comum ${ }^{6}$. Ocorre geralmente de três a 75 dias após o início da crise $\mathrm{e}^{5,6}$, evoluindo para um déficit máximo em torno de 30 dias se o tratamento não for iniciado ${ }^{5}$. Pode causar fraqueza, plegia ou arreflexia ${ }^{5}$, com estimativa que complique 10 a $40 \%$ dos casos de porfiria aguda ${ }^{6}$. Se inicia normalmente pelos membros superiores ${ }^{7,8}$, sendo a musculatura proximal a principal acometida em $80 \%$ dos $\operatorname{casos}^{5,6}$. Pode ser uni ou bilateral com flutuação da sua intensidade entre os dias $^{7}$. Ocorre comprometimento sensitivo em $60 \%$ dos pacientes, acometendo as extremidades dos membros (padrão em luva e bota) em metade dos casos e outra metade com comprometimento proximal $^{6}$, se manifestando como dor neuropática ou parestesia ${ }^{8}$. Os nervos cranianos também são acometidos em $75 \%$ das vezes $^{6}$ principalmente o III, VII e X pares ${ }^{7}$. No comprometimento extremo da doença, pode haver tetraplegia e insuficiência respiratória com necessidade de suporte ventilatório ${ }^{5}$, sendo esse último a principal causa de morbidade e mortalidade ${ }^{6}$.

\section{Disfunção do sistema nervoso central}

Envolve alterações do estado mental, desordens psiquiátricas e quadros epilépticos ${ }^{6}$. A alteração do estado mental pode ser com ansiedade, irritabilidade, insônia, inquietação, além de encefalopatia de graus variados, inclusive com rebaixamento do nível de consciência ${ }^{6,7}$. Desordens psiquiátricas podem ser diversas, sendo a depressão, as alucinações e delírios as mais comuns. No entanto, quadros de isolamento social, psicose, agressividade, hipomania e catatonia também são relatados ${ }^{6,7}$, inclusive com tentativas de suicídio ${ }^{7,13}$. Quadros convulsivos podem ser focais ou generalizados, raramente sendo a primeira manifestação da crise ${ }^{7}$.

Todo o quadro de neuropatia tende a regredir completamente após a crise da doença ${ }^{7-9}$. As manifestações autonômicas e do sistema nervoso central geralmente tem recuperação rápida ${ }^{5}$, porém a neuropatia tem regressão mais lenta, de forma progressiva a depender do extensão e intensidade da lesão axonal ${ }^{5}$. No entanto, podem persistir alguns sintomas residuais, sendo a fraqueza da musculatura distal e a perda sensorial as mais frequentes ${ }^{7}$. Após crises repetidas, há sobreposição da lesão neurológica, resultando em fraqueza crônica e hipotrofia muscular ${ }^{5}$.

O acometimento hepático não é comum nas porfirias. Apenas a protoporfiria eritropoiética, em uma parte pequena de indivíduos $(<10 \%)$ pode cursar com hepatopatia severa, cirrose e colestase ${ }^{9}$. O risco de carcinoma hepatocelular é aumentado na PV, PIA e $\mathrm{CPH} 10$, não estando relacionado com hepatopatia crônica ou aguda.

O principal diagnóstico diferencial é com a síndrome de Guillain-Barré, devido as manifestações clínicas semelhantes. Outra patologia é a intoxicação por chumbo, um metal pesado que leva a uma neuropatia idêntica à vista na porfiria ${ }^{6}$ - mas em geral 


\begin{tabular}{|c|c|c|c|c|}
\hline & $\begin{array}{l}\text { Atividade da } \\
\text { porfobilinogênio } \\
\text { deaminase em } \\
\text { eritrócitos }\end{array}$ & Porfirinas urinárias & Porfirinas fecais & Porfirinas séricas \\
\hline $\begin{array}{c}\text { Porfiria } \\
\text { Intermitente aguda } \\
\text { (PIA) }\end{array}$ & $\begin{array}{l}\text { Redução de } 50 \% \\
\text { em } 90 \% \text { casos }\end{array}$ & $\begin{array}{l}\text { Muito aumentada. } \\
\text { Princ. Uroporfirina }\end{array}$ & $\begin{array}{l}\text { Normal ou pouco } \\
\text { aumentada }\end{array}$ & $\begin{array}{l}\text { Normal ou pouco } \\
\text { aumentada }\end{array}$ \\
\hline $\begin{array}{l}\text { Coproporfiria } \\
\text { hereditária } \\
\text { (CH) }\end{array}$ & Normal & $\begin{array}{l}\text { Muito aumentada. } \\
\text { Princ. Coproporfirina }\end{array}$ & $\begin{array}{l}\text { Muito aumentada. } \\
\text { Princ. Coproporfirina }\end{array}$ & $\begin{array}{l}\text { Usualmente } \\
\text { normal }\end{array}$ \\
\hline $\begin{array}{c}\text { Porfiria Variegada } \\
\text { (PV) }\end{array}$ & Normal & $\begin{array}{l}\text { Muito aumentada. } \\
\text { Princ. Coproporfirina }\end{array}$ & $\begin{array}{l}\text { Muito aumentada. } \\
\text { Princ. Coproporfirina } \\
\text { e Protoporfirina }\end{array}$ & Muito aumentada \\
\hline
\end{tabular}

Tabela 1 - Achados laboratoriais para diferenciação das porfirias hepáticas agudas. Em destaque os principais pontos que permitem a classificação.

uma história de exposição a essa substância esclarece o diagnóstico. Deve-se distinguir quadros de vasculite e polimiosite ${ }^{6-8}$. Uma vez que na crise de porfiria ocorrem manifestações psiquiátricas, pode haver confusão diagnóstica com esquizofrenia, depressão e desordens de somatização ${ }^{6}$. O seu possível desencadeamento pelas variações hormonais na mulher pode resultar em um quadro de ansiedade e ser erroneamente diagnosticada como síndrome prémenstrual (popularmente conhecida como tensão pré-menstrual) ${ }^{7}$.laboratório do hospital no período de 10 meses, correspondentes a janeiro de 2012 a outubro de 2012. Foram avaliados somente amostras com resultado de antibiograma disponível. Foram excluídas as amostras do mesmo paciente com isolamento do mesmo patógeno.

\section{DIAGNÓSTICO}

As porfirias hepáticas agudas são facilmente reconhecidas quando se apresentam com sua tríade diagnóstica clássica de dor abdominal, neuropatia e alteração do estado mental ${ }^{6}$. No entanto, por ser uma doença rara, com sintomas inespecíficos e com uma ampla variedade em sua apresentação, pode haver erros diagnósticos, além de muitas vezes ele ser tardio ou mesmo não ocorrer ${ }^{6}$.

Inicialmente, deve-se dividir o diagnóstico da doença em dois grupos de pacientes: pacientes sintomáticos ou assintomáticos ${ }^{7}$.

Nos pacientes sintomáticos, este se baseia na história clínica associada ao aumento das porfirinas no sangue, urina e fezes ${ }^{9}$, indicando um acúmulo de intermediários da via do heme devido à deficiência enzimática.
Primeiramente, usa-se um teste qualitativo de triagem, com avaliação do porfobilinogênio urinário ${ }^{5,7-}$ 9. Diante de um resultado positivo, tem-se o diagnóstico de porfiria hepática aguda e está indicado o início do tratamento após coleta de material para exames subsequentes, sem que essa coleta cause atraso à terapêutica ${ }^{8}$. Esse teste de triagem será negativo apenas na porfiria por deficiência da ALA dehidratase - a qual é rara; quando o tratamento com heme já foi iniciado - já que ocorre um rápido decréscimo do valor dos precursores do heme com o tratamento; e em alguns casos de porfiria variegada e coproporfiria hereditária ${ }^{8}$. Diante de um teste negativo mas persistindo a suspeita clínica, novos exames devem ser colhidos sem que o diagnóstico seja excluído ${ }^{7}$.

Após o diagnóstico inicial, indica-se a coleta de novos exames para a diferenciação do tipo específico de porfiria hepática aguda. Realiza-se a dosagem quantitativa do ALA, porfobilinogênio e porfirinas no sangue, urina e fezes, além da avaliação da atividade enzimática das enzimas da via do heme $e^{5,8}$. A interpretação laboratorial dos resultados é muitas vezes confusa, com sobreposição dos valores ${ }^{5}$. No entanto, a proporção do aumento de cada intermediário mostra qual enzima encontra-se deficiente ${ }^{5}$, indicando o diagnóstico como exposto na tabela 1. É sempre recomendada a complementação com o teste genético e mensuração da atividade enzimática ${ }^{8}$. O aumento do ALA associado a níveis normais de porfobilinogênio sugere a porfiria por deficiência da ALA dehidratase; entretanto, outras condições devem ser excluídas, como intoxicação por chumbo e tirosinemia tipo 18.

Nos indivíduos assintomáticos, fora da crise aguda da doença, a dosagem de intermediários da via do heme não é útil, pois em sua maioria se encontrarão 
dentro dos valores normais ${ }^{7}$. Dessa forma, recorre-se à avaliação da atividade enzimática em eritrócitos e ao teste genético. Este último avalia diretamente no DNA a mutação de genes que codificam enzimas da via de síntese do heme, o qual permite um diagnóstico rápido e muito preciso ${ }^{8}$. Seu uso é de grande importância para avaliar indivíduos sob risco de exacerbação aguda da doença e nos familiares de pessoas afetadas pela porfiria ${ }^{8}$. Chama-se atenção para o fato de que $80 \%$ dos indivíduos com alguma mutação genética nunca desenvolverão sintomas ${ }^{5,8}$.

Outro teste que pode ser utilizado para indivíduos assintomáticos é a avaliação da atividade do porfobilinogênio deaminase nos eritrócitos, enzima essa que, se deficiente, causa a PIA. Essa avaliação é útil na triagem de familiares de um indivíduo afetado e para o diagnóstico da doença nos indivíduos com porfobilinogênio aumentado ${ }^{8}$, sendo que 0 valor normal da atividade enzimática não exclui o diagnóstico. Para a PV e $\mathrm{CPH}$, a quantificação da atividade enzimática é de grande dificuldade técnica, não sendo disponível rotineiramente.

\section{TRATAMENTO}

Geralmente o manejo da crise de porfiria é feito com o paciente internado ${ }^{8}$. Inicialmente deve-se suspender os fatores que possam ter desencadeado a exacerbação, assim como optar pelo uso apenas de medicações seguras na porfiria ${ }^{5-8}$.

O tratamento pode ser dividido em terapia sintomáti-ca/suportiva e terapia modificadora de doença ${ }^{5}$.

\section{Terapia sintomática/suportiva}

Se inicia com a monitoração do paciente. Atenção deve ser dada à reposição volêmica adequada, em especial se houver vômitos ou baixa ingesta, sempre atentando aos níveis de eletrólitos séricos ${ }^{5,9,14}$. O controle da dor pode ser feito com Paracetamol e/ou opióides $^{6,8,14}$, tendo-se em mente que podem ser necessárias altas doses de morfina ou meperidina ${ }^{14}$. Clorpromazina é recomendado para manejo da agitação e ansiedade14; betabloqueadores proporcionam um bom controle da hiperatividade simpática, assim como da hipertensão e taquicardia ${ }^{5-}$ 9,14; infecções concomitantes devem ser adequadamente tratadas, e sinais de insuficiência respiratória devidamente observados ${ }^{7,9}$. O tratamento de crises convulsivas requer cuidado, pois a maioria dos anticonvulsivantes podem exacerbar o quadro de porfiria ${ }^{6,8,9,14}$, sendo que a fenitoína, carbamazepina e fenobarbital devem ser evitados ${ }^{6,14}$. O tratamento deve ser com gabapentina, podendo-se optar pelo propofol em crises refratárias ${ }^{6}$.

\section{Terapia modificadora de doença}

É direcionado à supressão da enzima ALA sintase $^{5,6,8,14}$, e deve ser iniciada tão logo quanto possível, pois altera o prognóstico do paciente e a evolução do quadro ${ }^{7,8}$. Sendo essa enzima o passo limitante de toda a via de formação do heme $e^{5-8}$, sua supressão leva à redução de intermediários tóxicos da via ${ }^{5-8}$, reduzindo assim a lesão neurológica e possibilitando a melhora clínica.

A terapia padrão baseia-se na infusão endovenosa de glicose de 300-400 gramas ao dia $^{5,6,8,14}$, atentando-se para hiponatremia induzida pelo solução glicosada ${ }^{5-9,14}$. A terapia com hematina ou hemina, um complexo férrico tetrapirrólico semelhante ao heme humano, é a primeira escolha para o tratamento $^{7-9}$. É um inibidor da $\operatorname{ALAS}^{6,8,14}$, sendo usado com sucesso nas crises, superando a terapia padrão com glicose ${ }^{8}$. No entanto, como esse medicamento ainda não esta disponível no Brasil ${ }^{15}$ e pelo seu alto custo, seu uso ainda é restrito. A dose de hemina (Normosang ${ }^{\circledR}$ ) recomendada é de $3-4 \mathrm{mg} / \mathrm{Kg} / \mathrm{dia}$, endovenoso, a cada 24 horas durante três a quatro dias $^{6,8}$. Se iniciada precocemente, uma melhora clínica é esperada em um a dois dias ${ }^{6}$. O uso por um período mais prolongado pode ser considerado em caso de resposta clínica pobre após esse período ${ }^{6}$. Deve-se ter em mente que a lesão neurológica axonal demora para regredir, não melhorando de imediato após a terapia adequada $^{5}$. Apesar deste tratamento ser útil na agudização da doença, ela não previne novas exacerbações no futuro ${ }^{6}$, além de não agir nos sintomas que permanecem a longo prazo ${ }^{6}$.

$O$ transplante de fígado tem sido feito com sucesso em pacientes com PV e PIA, com a normalização bioquímica e prevenção das crises da doença ${ }^{6}$.

A terapia genética é a expectativa de tratamento para o futuro, com pesquisas em andamento com genes da PIA ${ }^{6,8}$.

\section{ACOMPANHAMENTO E PROGNÓSTICO}

O acompanhamento dos pacientes com porfiria é pautado na prevenção das crises ${ }^{5,6}$. A educação do paciente e identificação de fatores que possam desencadeá-la é muito importante na prevenção $^{8}$.

O uso de medicações deve ser minimizado ${ }^{5}$ e limitado às drogas sabidamente seguras na porfiria ${ }^{5-}$ 8,10 , pois diversas medicações podem desencadear crises da doença ${ }^{5-8,10}$. Todo medicamento necessário deve ser consultado quanto a sua segurança, que pode ser avaliado em diversas listas, disponibilizadas em web sites dedicados ao assunto, como os abaixo: http://db.porphyriafoundation.com/forms/drug- 


\section{ARTIGO DE REVISÃO}

search.lasso e http://www.porphyria-europe.com/03drugs/selecting-drugs.asp.

Além disso, estes pacientes devem evitar dieta com restrição de carboidratos ou jejum prolongado ${ }^{5,7}$. Devem manter uma ingestão oral satisfatória para manutenção do peso com o acompanhamento nutricional adequado e devem abster-se do consumo de bebidas alcoólicas e uso de tabaco ou drogas ${ }^{7,8}$. Em mulheres nas quais as crises são desencadeadas pela menstruação, o uso de análogos do GNRH é uma opção ${ }^{7,14}$.

O prognóstico em geral é bom ${ }^{5,7,8}$, principalmente naqueles pacientes que conseguem evitar fatores desencadeantes da crise aguda e nos que recebem pronto tratamento durante as exacerbações ${ }^{7,8}$.

\section{CONCLUSÃO}

Como a crise de porfiria é incomum e por se manifestar de forma inespecífica, o diagnóstico muitas vezes é demorado, o que atrasa o tratamento e piora o prognóstico. Deve-se ter alta suspeição clínica, com realização de exames diagnósticos adequados. O tratamento deve ser iniciado mesmo na suspeita clínica caso exames confirmatórios não possam ser realizados. Há um aumento da morbimortalidade com o atraso na terapia, o que pode prolongar o tempo de internação, aumentando assim o risco de infecções e outras complicações possíveis, além de piorar a extensão e intensidade da lesão neurológica pelos produtos tóxicos da via do heme, prolongando o tempo de recuperação da neuropatia.

\section{REFERÊNCIAS BIBLIOGRÁFICAS}

1.FAUCI AS et al. Harrison Medicina Interna. 17 a edição. 2v. Rio de Janeiro: McGraw Hill interamericana do Brasil, 2008. p.2434-2444.

2.ANDERSON KE, Porphyrias: An overview. Disponível em: http://www.uptodate.com/. Acesso em: 18/03/2013.

3.THOMAS MD et al. Manual de Bioquímica com Correlações Clínicas. 7ạ edição. Editora Blucher; 2011. p. 814-819.

4.MORAES CT; DIAZ F; BARRIENTOS, A. Defects in the Bio-synthesis of Mitochondrial Heme $c$ and Heme $a$ in Yeast and Mammals. Biochimica et Biophysica Acta. 2004;1659:153-159.

5.ALBERTS JW; FINK JK Porphyric Neuropathy. Muscle Nerve 2004;30:410-422.

6. SIMON NG; HERKES GK The Neurologic manifestations of the Acute porphyrias. Journal of Clinical Neuroscience. 2011;18:1147-1153.

7.CRIMLISK HL; The Little imitator - Porphyria: a Neuropsy-chiatric Disorder. Journal of Neurology, Neurosurgery, and Psychiatry .1997;62:319-328.
8.ANDERSON KE et al. Recommendations for the Diagnosis and Treatment of the Acute Porphyrias. Annais of Internal Medicine. 2005;142:439-450.

9.CHEMMANUR AT; BONKOVSKY HL Hepatic Porphyrias: Diagnosis and Management. Clinics in Liver Disease. 2004;8:807-838.

10.SASSA S; Modern Diagnosis and Management of the Porphyrias. Br J Haematol. 2006;135:281-292.

11.THADANI H; DEACON A; Peters T Diagnosis and Man-agement of Porphyria. BMJ 2000;320:1647-1651.

12.RIDLEY A; HIERONS R; CAVANAGH JB Tachycardia and the Neuropathy of Porphyria. Lancet 1968;2:708-710.

13.EL-SHAZLY M; Acute Intermittent Porphyria: A Family Study. Bry Hosp Med. 1995;53:169-170.

14.KALMAN DR; BONKOVSKY HL, Management of Acute Attacks in the Porphyrias. Clinics in Dermatology. 1998;16:299-306.

15. Ministério da Saúde. Consultoria Jurídica/Advocacia Geral da União - Nota Técnica N³5 /2012. Brasília: 2012. Disponível em: http://portalsaude.saude.gov.br/portalsaude/arquivos/pdf/2013/Ma r/22/hemina_hematina.pdf. Acesso em: 05/04/2013.

16.American Porphyria Foundation. Disponível em: <http://www.porphyriafoundation.com>. Acesso em: 03/-04/2013.

17.Europian Porphyria Network. Disponível em: <http://www.porphyria-europe.org/index.asp>. Acesso em: 03/04/2013.

18.LEVIN KH; Variants and Mimics of Guillain Barré Syn-drome. The Neurologist. 2004;10:61-74. 